Dr Slavko Pokorni, pukovnik, dipl. inž.

Vojna akademija Beograd

\section{STATISTIČKA ANALIZA BEZBEDNOSTI TEHNIČKIH SISTEMA U TOKU EKSPLOATACIJE}

UDC: $62-7: 311.7$

Rezime:

U radu su prikazane osnove teorije bezbednosti tehničkih sistema. Ukratko je prikazan razvoj teorije bezbednosti proizvoda, analiziran je odnos pojmova pouzdanost i bezbednost proizvoda, kao i drugih koji se koriste $u$ istom smislu. Dati su i osnovni pojmovi iz oblasti bezbednosti tehničkih sistema, kao i pokazatelji i indikatori bezbednosti tehničkih sistema. Analizirani su osnovni principi ostvarivanja bezbednosti tehničkih sistema i prikazani osnovi statističke analize bezbednosti tehničkih sistema u eksploataciji na osnovu predznaka o mogućnosti nastanka udesa.

Ključne reči: bezbednost, tehnički sistem, eksploatacija, šteta, udes.

\title{
STATISTICAL ANALYSIS OF TECHNICAL SYSTEMS SAFETY DURING THEIR USAGE
}

Summary:

The fundamentals of theory of technical systems safety are presented in this paper. A short history of theory of product safety is given and relationship between reliability and safety terms is analyzed as well as other similar terms. The basic terms from technical systems safety area are given as well as index and indicators of the technical systems safety. The basic principles of technical systems safety are analyzed and the fundamentals of statistical analysis of technical systems safety during usage, based on indices of possibility of accident are shown.

Key words: technical systems, safety, usage, statistical analysis, harm, accident.

\section{Uvod}

Bezbednost rada jedna je od osnovnih osobina koje se tiču kvaliteta, pogotovo ako se ima u vidu pravo društva i pojedinca da budu zaštićeni od tereta i usluga opasnih po zdravlje i život. Praksa, u svetu, svedoči o porastu broja nesrećnih slučajeva, trauma i drugih nezgoda, odnosno vanrednih događaja u vojsci, zbog nedovoljnog nivoa bezbednosti. Održavanje tehničkih sistema u tome nije izuzetak, već negativan primer. Zbog sve starije tehnike koja se koristi, nemogućnosti njene zamene, želje da se izvrši zadatak po svaku cenu, pri čemu se zanemaruju neka pravila pri upotrebi, i niza drugih faktora, može se reći da je problem bezbednosti tehničkih sistema u toku njihove eksploatacije dobio globalni značaj.

Radi toga veoma je važna razrada metodologije upravljanja bezbednošću tehničkih sistema u eksploataciji.

Primena teorije bezbednosti tehničkih sistema, u našoj vojsci, mogla bi da ima korisne efekte u preventivi udesa, 
odnosno vanrednih događaja, pogotovo onih sa teškim posledicama (prvenstveno smanjenju vanrednih događaja sa smrtnim posledicama, povredama i velikim materijalnim štetama).

U radu su korišćene sledeće oznake i skraćenice: otkaza,

FMECA - analiza vrste i kritičnosti

$\mathrm{G}$ - gotovost,

$\mathrm{K}$ - kritičnost otkaza,

$\mathrm{M}(\mathrm{N})$ - matematičko očekivanje broja nepoželjnih događaja,

$\mathrm{n}$ - specifično srednje vreme nepoželjnih događaja,

$\mathrm{N}$ - broj nepoželjnih događaja,

NNE - narušavanje normalne eksploatacije,

RIZ - rizik,

$\mathrm{R}_{\mathrm{pr}}$ - granica rejtinga NNE za verovatnoću poverenja veću od 0,5 ,

$\mathrm{R}(\mathrm{t})$ - verovatnoća ispravnog rada (pouzdanost),

SUO - stanje u otkazu,

SUR - stanje u radu,

$\mathrm{T}$ - vreme do otkaza.

\section{Razvoj teorije bezbednosti proizvoda}

Teorija bezbednosti proizvoda, a prema tome i tehničkih sistema, kao samostalna naučna disciplina, formirana je šezdesetih i sedamdesetih godina 20. veka, sa razvojem naučnotehničke revolucije. Treba napomenuti da je u oblasti ostvarivanja bezbednosti proizvoda dugo vladala koncepcija „apsolutne bezbednosti“, kod koje se pretpostavljalo da se determinističkim proračunom, uz analizu najgorih varijanti udesa, i uzimanjem u obzir rezer- ve pri projektovanju, postiže bezbednost objekta u upotrebi. Međutim, time je ignorisan slučajni karakter incidenata uslovljenih nizom malo verovatnih uzroka koji nisu uzimani u obzir u toku proračuna. Tome je doprinelo nekoliko uzroka.

Najpre, po pravilu, u analizama mogućih scenarija udesa nisu uzimani u obzir mogući načini prerastanja poremećaja normalne eksploatacije u udes, već samo najgora moguća varijanta. Smatralo se da nastupanje i te najgore varijante neće imati posledice veće od predviđenih projektom, tj. iako se proizvod (objekat) nije mogao smatrati potpuno bezbednim, ipak je smatrano da će posledice biti ograničene. Ovakav pristup praksa je opovrgla. Drastičan primer su udesi do kojih je došlo u Černobilu i pri lansiranju Čelindžera.

Takođe, za većinu tehničkih sistema nisu bili definisani pokazatelji bezbednosti, a zbog toga nisu bili predviđeni ni ciljevi upravljanja i prikupljanja neophodnih informacija o bezbednosti. Osim toga, dugo vremena se smatralo neprikladnim da se rizik uzima u obzir kao pokazatelj bezbednosti, što je, u krajnjem, vodilo ignorisanju principa da se odluka donosi na osnovu činjenica.

Spoznaja o slučajnom karakteru uzroka udesa dovela je do promene pristupa ostvarivanju bezbednosti, pa je danas, u svetu, prihvaćena koncepcija prihvatljivog rizika, u čijoj su osnovi metode analize bezbednosti zasnovane na matematičkoj statistici i teoriji verovatnoće.

Norme (kriterijumi) rizika zavise od stepena ekonomskog razvoja. Što je viši nivo ekonomskog razvoja i kulture bezbednosti, to su viši zahtevi za bezbednost potencijalno nebezbednih proizvoda, a time niži nivoi prihvatljivog rizika. 
Može se reći da je uvođenje rizika od udesa, kao univerzalne karakteristike bezbednosti, predstavljalo jednu vrstu revolucije u pristupu upravljanju bezbednošću. Takav pristup već je dao značajne rezultate, i omogućio predviđanje udesa i konačno formiranje teorije bezbednosti. Metode teorije pouzdanosti mogu se primeniti i u teoriji bezbednosti, ali pored proračuna verovatnoće otkaza treba proceniti i posledice tih otkaza.

Tokom razvoja teorije bezbednosti, po pravilu, analizirana je bezbednost proizvoda, npr. tehničkog sistema. Međutim, bezbednost je važna karakteristika kvaliteta, ne samo proizvoda već i usluga, kao što je održavanje tehničkih sistema. U [6] se koristi zajednički naziv ,proizvod“"1, koji se definiše kao „rezultat procesa“, a u napomeni se kaže da postoje četiri generičke kategorije proizvoda: usluge (npr. transport); softver (npr. računarski program, rečnik); hardver (npr. mehanički deo mašine) i procesni materijali (npr. sredstvo za podmazivanje). Praksa pokazuje da su i mnoge usluge potencijalni izvori opasnosti, pa ih treba analizirati sa aspekta bezbednosti. Za to se mogu koristiti i već poznate metode u teoriji pouzdanosti, npr. FMECA (analiza vrste i kritičnosti otkaza) [1], koja analizira uticaj tehnoloških operacija na bezbednost sredstva koje se održava, odnosno remontuje, ali i uticaj operacija na bezbednost samog procesa održavanja (nepridržavanje nekih od operacija može imati kritične posledice po proces održavanja - uticaj na sredstvo pri tome se ne uzima u obzir).

\footnotetext{
${ }^{1}$ Mnogi proizvodi sadrže elemente koji pripadaju različitim generičkim kategorijama proizvoda. Od dominantnog elementa zavisi da li će se neki proizvod nazvati usluga, softver, hardver ili procesni materijal.
}

Primena teorije bezbednosti u eksploataciji proizvoda (naoružanja i vojne opreme, tehničkih sistema i sl.), u vojsci ima veliki značaj, posebno u smanjenju tzv. vanrednih događaja.

\section{Bezbednost tehničkih sistema}

U domaćoj literaturi koriste se različiti termini za pojam bezbednost. Tako se, u prevodu naslova [1], koristi termin sigurnost, koji potiče od engleskog $s a$ fety, odnosno ruskog bezopasnost.

Međutim, u [5] je engleski termin safety, preveden kao bezbednost i ima značenje ,odsustvo neprihvatljivih rizika od štete", pri čemu se u napomeni dodaje: „U standardizaciji ${ }^{2}$ bezbednost proizvoda, procesa ili usluga uglavnom ima za cilj optimalnu uravnoteženost niza faktora, uključujući i netehničke faktore kao što je ljudsko ponašanje, da bi se rizici i štete (koji se mogu izbeći) ljudima i dobrima otklonili do prihvatljivog nivoa".

Analiza sadržaja pokazuje da je u [1] ruski termin bezopasnost korišćen upravo u smislu kako je definisan u [5] pod nazivom bezbednost.

$\mathrm{U}$ [6], u delu za termine koji se odnose na karakteristike kvaliteta, definisan je pojam sigurnost funkcionisanja (engl. dependability) u značenju ,skup svojstava koji opisuje raspoloživost i faktore koji na nju utiču: pouzdanost, pogodnost održavanja i logistička podrška održavanju“. U napomeni se kaže: „Sigurnost funkcionisanja koristi se samo za opšte opisivanje i nije kvantitativnog karaktera". Pri tome se poziva na IEC 60050-191:1990.

\footnotetext{
${ }^{2}$ Standardizacija prema [5] predstavlja aktivnost na utvrđivanju odredbi za opštu i višekratnu upotrebu, u odnosu na stvarne ili potencijalne probleme, radi postizanja optimalnog nivoa uređenosti u datom kontekstu.
} 
Pojam bezbednost, u smislu kao u ovom radu, koristi se i u [2, 8]. U [2] piše: „U praksi se često, pored pojma pouzdanost, sreće i pojam bezbednost. Bezbednost podrazumeva čuvanje ljudskih života i njegovih efektiva i razmatra moguće tipove, razloge i efekte otkaza koji utiču na ličnu bezbednost osoblja koje koristi ili održava sisteme. Često se i bezbednost prikazuje kao verovatnoća da se neće dogoditi otkaz sistema koji dovodi do ugrožavanja života ljudi. Ovakvi otkazi su kritični otkazi. Kako se u okviru pouzdanosti analiziraju svi otkazi i efekti otkaza i određuje verovatnoća otkaza, to znači da pouzdanost šire i sveobuhvatno razmatra problematiku otkaza, a bezbednost uže i samo u vezi sa otkazima koji utiču na sigurnost ljudi““.

Tako su prevagnuli razlozi da se u ovom radu koristi termin bezbednost umesto sigurnost. Uostalom, autor je termin bezbednost, $\mathrm{u}$ značenju kao u ovom radu, već koristio u [2].

\section{Osnovni pojmovi iz oblasti bezbednosti tehničkih sistema}

U osnovi pojmova koji se odnose na bezbednost je prvenstvo koje se daje zaštiti čoveka kao društvene jedinke, odnosno o ljudskim pravima, što je u skladu sa međunarodnim dokumentima, kao što je Rezolucija Generalne skupštine Ujedinjenih nacija iz aprila 1985. godine broj 39/248. Tu se bezbednost razmatra kao tehnoekonomska osobina proizvoda, i kao osnovni koristi se pojam šteta, pod kojim se podrazumeva pripadajuća karakteristika stanja proizvoda, koja odražava proces pogoršanja kvaliteta proiz- voda [1]. Iz tog pojma logično se izvode dve osobine proizvoda:

- nebezbednost proizvoda - osobina proizvoda koja karakteriše njegovu sposobnost da nanese štetu;

- bezbednost proizvoda - osobina proizvoda koja karakteriše njegovu sposobnost da spreči nastanak štete ili ograniči njenu veličinu.

Prema tome, sva moguća stanja proizvoda celishodno je razdvojiti na bezbedna i nebezbedna. S obzirom na to da praktično neprekidno postoje uzroci koji mogu dovesti do nebezbednog stanja, a prema tome i štete, potrebno je odrediti veličinu štete do koje se smatra da je objekat bezbedan, u skladu sa odgovarajućim kriterijumom (tehničkim, ekonomskim ili društvenim).

Zbog toga se uvodi pojam prihvatljiva šteta, koja označava krajnju veličinu štete nakon koje kvalitet proizvoda pada ispod dozvoljene vrednosti. $\mathrm{Na}$ osnovu nje lako se definišu pojmovi:

- nebezbedno stanje, kao stanje koje nastupa kada je šteta premašila vrednost prihvatljive štete,

- bezbedno stanje, kao stanje kada je šteta ispod vrednosti prihvatljive štete.

Dalje pogoršanje stanja proizvoda, usled delovanja uzroka nebezbednosti, može se dovesti u vezu sa nivoom štete koji se može nazvati dozvoljenom štetom.

Stanje proizvoda koje nastaje kada šteta premaši veličinu dozvoljene štete može se nazvati udes ili havarija.

Stanje proizvoda kada je on sposoban da ispunjava zahtevane funkcije naziva se ispravno stanje ili stanje u raduSUR [2]. Sa stanovišta bezbednosti objekat može iz stanja u radu preći u stanje u otkazu (SUO) koje može biti bezbedno 
ili nebezbedno. Prelaz proizvoda iz stanja $\mathrm{u}$ radu u bezbedno stanje $\mathrm{u}$ otkazu može se nazvati poremećaj (narušavanje) normalne eksploatacije (NNE). Sa stanovišta pouzdanosti prelaz proizvoda iz stanja u radu u stanje u otkazu naziva se otkaz. Prema tome, NNE može biti povezano sa otkazom nekog dela (elementa) sistema.

Međutim, ne dovode samo otkazi do $N N E$. Do $N N E$ može dovesti i nepredviđeni nepravilni postupak čoveka-operatora, ili propust da se preduzme potreban pravilni postupak, što se naziva greška čoveka.

Prelaz proizvoda iz SUR u nebezbedno SUO naziva se nezgoda, a prelaz iz $S U R$ u havarijsko stanje udes.

Svi događaji u vezi sa nebezbednošću mogu se nazvati incidenti.

Klasifikacija događaja i stanja proizvoda u vezi sa bezbednošću prikazana je na slici 1 .

Incident (NNE, nezgoda i udes) karakteriše se uzročnim (incidentnim) događajem, tokom nastanka i posledicama (veličinom štete). Uzročni događaji mogu biti otkazi elemenata proizvoda, greške čoveka ili spoljnji (u odnosu na objekat) događaji - požari, udari groma, poplave, itd.

Radi klasifikacije otkaza elemenata proizvoda, sa stanovišta njihovog uticaja na bezbednost, uvodi se pojam kritičnosti otkaza, pod kojim se podrazumeva skup karakteristika koje karakterišu posledice otkaza. Za kriterijum klasifikacije mogu se uzeti direktni ili indirektni gubici izazvani otkazom (uključujući i gubitke izazvane uništenjem samog proizvoda). Po kritičnosti, otkazi se dele na:

- kritične, čije posledice dovode do prelaska proizvoda u stanje udesa,

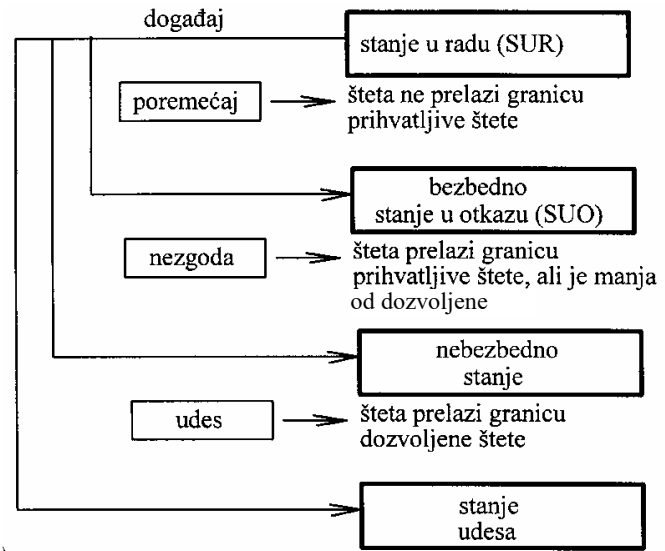

Sl. 1 - Klasifikacija osnovnih dogadaja i stanja pri analizi bezbednosti proizvoda

- važne, koji pri prelasku proizvoda $\mathrm{u}$ nebezbedno ili bezbedno stanje u otkazu imaju za posledicu samo znatne ekonomske gubitke (štete),

- nevažne (sporedne), ako su posledice prelaska proizvoda u bezbedno stanje u otkazu samo neznatni ekonomski gubici.

Prema tome, pri analizi bezbednosti treba prvenstveno analizirati kritične otkaze. U tome je suština povezanosti pouzdanosti i bezbednosti proizvoda.

\section{Pokazatelji i indikatori bezbednosti}

Pokazatelj je veličina koja predstavlja kvantitativnu karakteristiku odgovarajuće osobine proizvoda. Kako je i bezbednost osobina proizvoda, celishodno je formirati skup pokazatelja koji kvantitativno karakterišu tu osobinu.

Formiranje pokazatelja bezbednosti zasniva se na primeni odgovarajućih principa izbora pokazatelja, kao što su neophodnost (međusobna nezavisnost pokazatelja), dovoljnost, usklađenost sa 
definicijom osobine koju karakterišu [1]. Ako se pođe od toga da se udes karakteriše sa tri faktora: uzročni događaj, tok dešavanja udesa i konačno stanje proizvoda posle udesa (posledice), primenom ovih principa mogu se uvesti i tri grupe pokazatelja bezbednosti:

- pokazatelji koji karakterišu uzročne događaje (na primer, učestalost uzročnih događaja);

- pokazatelji koji karakterišu tok dešavanja udesa (na primer, srednje vreme dešavanja udesa);

- pokazatelji koji karakterišu konačno stanje proizvoda posle udesa (na primer, srednja veličina štete).

Pokazatelji se mogu odnositi samo na jednu grupu (pojedinačni), ali i na više grupa (složeni). Međutim, mogu se odnositi samo na specifičnost jednog proizvoda (posebni) ili primeniti na više proizvoda (univerzalni). Od univerzalnih pokazatelja osnovni su sledeći: - pouzdanost, gotovost, - operativna gotovost, - kritičnost otkaza, - specifično srednje vreme nepoželjnih događaja i rizik.

Pouzdanost se definiše kao verovatnoća ispravnog rada $R(t)$ i često je $u$ direktnoj vezi sa posebnim pokazateljima.

Gotovost $\mathrm{G}$ definiše se za ustaljeno stanje, a ne uzimaju se u obzir intervali kada se planski ne predviđa korišćenje proizvoda (vreme za preventivno održavanje, remont, planirano skladištenje ili transport).

Operativna gotovost $\mathrm{G}_{\mathrm{o}}$ može se odrediti izrazom:

$G_{o}=G \cdot R\left(t_{z}\right)$

gde je: $-\mathrm{R}\left(\mathrm{t}_{\mathrm{z}}\right)$ pouzdanost za koju se smatra da ne zavisi od prethodnog vremena $t$, već samo od zadatog intervala $t_{z}$, a do intervala vremena $t_{z}$ smatra se da gotovost ima vrednost G. Prethodni izraz podrazumeva da vreme rada do otkaza podleže eksponencijalnoj raspodeli.

Kritičnost otkaza K podrazumeva neki broj iz unapred zadatog opsega (bezdimenzionalna veličina) koji karakteriše posledice otkaza. Što je veća vrednost K, to su posledice otkaza veće. Kritičnost otkaza može karakterisati pouzdanost ili bezbednost. Ako je otkaz važan ili nevažan (samo u ekonomskom smislu) kritičnost otkaza karakteriše pouzdanost proizvoda, a ako je otkaz kritičan odgovarajuća vrednost $\mathrm{K}$ karakteriše bezbednost proizvoda.

Specifično srednje vreme nepoželjnih događaja $\mathrm{n}$ predstavlja matematičko očekivanje broja nepoželjnih događaja (otkaza, NNE, nezgoda, udesa) i definiše se relacijom:

$n=\frac{M(N)}{T}$

gde je $M(N)$ matematičko očekivanje broja nepoželjnih događaja N (otkaza, NNE, nezgoda, udesa) koji se dešavaju za vreme rada do otkaza T. Ovaj pokazatelj važi za objekte istog tipa.

Rizik RIZ je verovatnoća nastanka unapred predviđenih neželjenih posledica (na primer, udesa sa predviđenom štetom). Što je rizik veći objekat je manje bezbedan. U opštem slučaju rizik se izračunava relacijom [1]:

$R I Z=$ verovatnoća (šteta $>$ dozvoljene štete)

Međutim, prema savremenim postavkama teorije rizika, rizik se računa kao $[9,10]$

RIZIK = verovatnoća $\mathrm{x}$ posledice 
$\mathrm{Na}$ osnovu prethodnih relacija očigledno je da mere bezbednosti proizilaze iz analize udesa (pretpostavljenih ili onih koji su se već dogodili).

Indikator, za razliku od pokazatelja bezbednosti, karakteriše ne samo bezbednost proizvoda, već odražava i stepen uticaja organizacije projektovanja i eksploatacije proizvoda na njegovu bezbednost.

Pokazatelji i indikatori bezbednosti treba da karakterišu bezbednost proizvoda u bilo kojoj fazi njegovog životnog ciklusa. Zbog toga se može govoriti o projektnim, eksploatacionim i sl. pokazateljima (indikatorima) bezbednosti, što omogućava da se analiziraju tendencije promene pokazatelja bezbednosti u toku projektovanja i proizvodnje proizvoda. Međutim, dok su pokazatelji bezbednosti nezavisni od faze životnog ciklusa (menja se samo njihova brojna vrednost), indikatori bezbednosti su bitno zavisni. Na primer, u fazi projektovanja kao indikator bezbednosti može se koristiti broj dorada na crtežima posle sprovedenih kontrola ili kritičnih neslaganja u projektnoj dokumentaciji.

Na izbor pokazatelja utiče i mogućnost da se oni proračunaju, pa se često oni koje nije moguće proračunati (zbog nedovoljno podataka) izostavljaju. Zavisno od osnove proračuna, pokazatelji bezbednosti mogu su podeliti i na determinističke i statističke, a od toga kako njihova vrednost utiče na nivo bezbednosti - na pozitivne i negativne. Pozitivni su oni kod kojih povećanje vrednosti pokazatelja daje viši nivo bezbednosti, a kod negativnih je suprotno. Prema tome, pokazatelji kao što su rizik i kritičnost spadaju u statističke složene univerzalne negativne pokazatelje bezbednosti. Klasifikacija pokazatelja (indikatora) bezbednosti prikazana je na slikama 2, 3 i 4 .
Pokazatelji bezbednosti, po karakteru određivanja, spadaju u grupu statističkih. Stoga je i osnovni matematički aparat matematička statistika i teorija verovatnoće, pa se i proračun pokazatelja i analiza bezbednosti proizvoda naziva statističkom analizom bezbednosti.

\section{Osnovni principi ostvarivanja bezbednosti tehničkih sistema}

Do sada su u svetu razrađeni opšti univerzalni principi ostvarivanja bezbednosti potencijalno opasnih proizvoda. Zavisno od konkretnog sistema, ti principi mogu se dopunjavati i/ili adaptirati. Dok se došlo do tih principa svet je platio veliku cenu, jer su oni rezultat analize udesa i nezgoda koji su se desili, ali i iskustava iz upotrebe potencijalno nebezbednih proizvoda. Osnovni principi su [1]: princip duboko ešelonirane zaštite i princip reagovanja na pojedinačni otkaz.

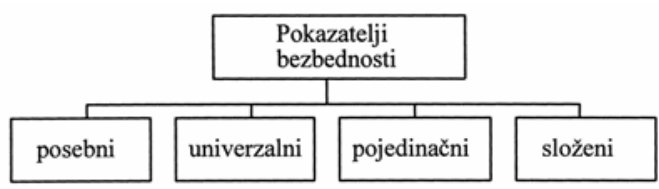

Sl. 2 - Vrste karakteristika bezbednosti

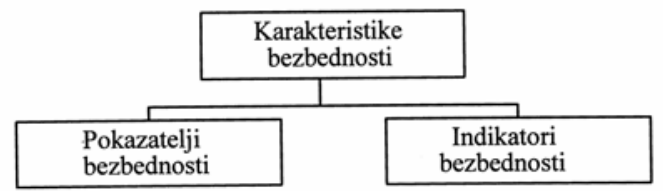

Sl. 3 - Klasifikacija pokazatelja bezbednosti

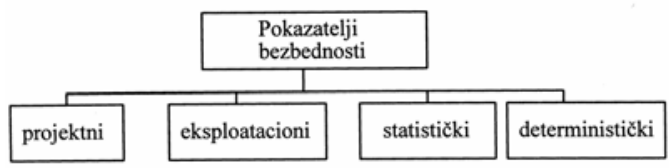

Sl. 4 - Klasifikacija pokazatelja bezbednosti $u$ zavisnosti od faze životnog ciklusa i načina proračuna 
Princip duboko ešelonirane zaštite ima posebno mesto među osnovnim principima i pretpostavlja formiranje niza uzastopnih nivoa zaštite od mogućih otkaza elemenata proizvoda i grešaka čoveka, među kojima su:

- postavljanje niza fizičkih prepreka (barijera) na putu prostiranja energije ili radi otklanjanja mogućnosti dolaska $u$ dodir sa opasnim delovima proizvoda;

- preduzimanje tehničkih i administrativnih mera radi zaštite celovitosti i efektivnosti ${ }^{3}$ tih prepreka.

Pouzdanost barijera se, kao i pouzdanost proizvoda, ugrađuje u toku projektovanja, obezbeđuje u toku proizvodnje i podržava u toku eksploatacije. Tehničko stanje barijere kontroliše se u toku upotrebe, a ako nije u skladu sa zahtevima upotreba sistema, u kome se ona koristi prekida se do uspostavljanja ispravnog stanja.

Ispravnost barijera i bezbednost proizvoda ostvaruje se nizom tehničkih i administrativnih mera [1].

Princip duboko ešelonirane zaštite, sa stanovišta bezbednosti, primenjuje se u skladu sa situacijom (slika 5).

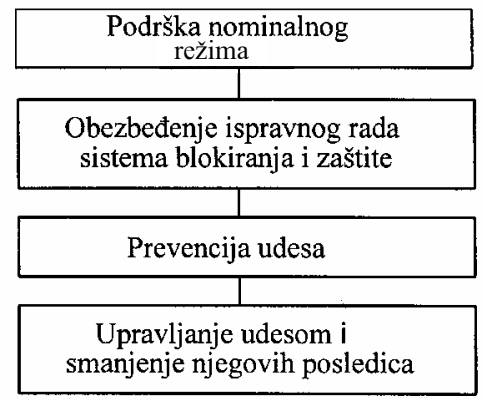

Sl. 5 - Primena principa duboko ešelonirane zaštite

${ }^{3} \mathrm{U}[6]$ u delu za termine koji se odnose na menadžment (3.2), efektivnost (engl. effectiveness) definiše se kao „Mera realizacije planiranih aktivnosti i planiranih rezultata"
Princip reagovanja na pojedinačan otkaz sastoji se u tome da sistem blokiranja i zaštite treba da ispunjava svoje funkcije kad god je to potrebno, i nezavisno od toga da li je otkazao neki element sistema blokiranja i zaštite. Sistem zaštite se uključuje pri otkazu elementa proizvoda ili pri grešci čoveka - operatora. U praksi se to ostvaruje rezerviranjem elemenata sistema zaštite. Da bi se obezbedila primena ovog principa, preduzimaju se različite mere rezerviranja i zaštite od otkaza, među kojima su, na primer, fizičko razdvajanje rezerviranih elemenata, različitost osnovnog i rezervnog elementa (ali obavljaju istu funkciju), itd.

\section{Statistička analiza bezbednosti tehničkih sistema u eksploataciji na osnovu predznaka o mogućnosti nastanka udesa}

Kao što je u uvodu napomenuto, zbog sve starije tehnike u upotrebi, nemogućnosti njene zamene, pa i subjektivnih razloga, pri čemu se zanemaruju neka pravila pri upotrebi, kao i niza drugih faktora, može se reći da problem bezbednosti tehničkih sistema $\mathrm{u}$ toku njihove eksploatacije ima ogroman značaj. Zbog toga je važna i neophodna razrada metodologije upravljanja bezbednošću tehničkih sistema u eksploataciji.

Pri analizi bezbednosti tehničkih sistema (proizvoda) sve događaje je pogodno grupisati na poremećaje, nezgode i udese, kao što je to pokazano na slici 1 .

U praksi, u toku upotrebe tehničkih sistema (TS), najčešće se registruju poremećaji, ređe nezgode, a vrlo retko udesi. Broj poremećaja eksploatacije je za nekoliko redova (10 do 100 puta) veći od 
ozbiljnih nezgoda i udesa. Zbog toga je logično da se operativno upravljanje bezbednošću zasnuje na rezultatima analize poremećaja. Pri tome treba imati u vidu da u uslovima ograničenih vremenskih i finansijskih resursa, mere koje će se preduzimati zavise od stepena opasnosti poremećaja. To ukazuje na potrebu da se definišu pokazatelji koji karakterišu težinu poremećaja, kao i odgovarajući metodi ocene uvedenih pokazatelja na osnovu eksploatacionih podataka.

Poremećaji sadrže dosta informacija o bezbednosti proizvoda, a njihova analiza, pa i statistička, omogućava izdvajanje faktora koji mogu dovesti do udesa.

Obični pokazatelji pouzdanosti, kojima se najčešće operiše radi analize bezbednosti u fazi eksploatacije, nisu dovoljni, jer ne karakterišu težinu poremećaja. Važna karakteristika poremećaja bila bi koliko je poremećaj blizak udesu. Zbog toga, kada se obavlja analiza bezbednosti proizvoda u eksploataciji, na primer, po broju poremećaja u jedinici vremena $n$, to $n_{A}<n_{B}$ ne znači $i$ da je objekat $A$ bezbedniji od proizvoda $B$, jer se može ispostaviti da su poremećaji proizvoda A bliži udesu nego poremećaji proizvoda B. Prema tome, klasični pokazatelji pouzdanosti nisu dovoljni za potpunu karakterizaciju bezbednosti proizvoda i potrebno je uvesti nove.

Da bi se korektno razmotrili pokazatelji rizika koji karakterišu bezbednost $\mathrm{u}$ toku upotrebe, korisno je poslužiti se modelom razvoja poremećaja, koji se može prikazati preko modifikovanog, $\mathrm{u}$ teoriji pouzdanosti već poznatog stabla događaja [7]. Pri tome se težina datog poremećaja ocenjuje preko verovatnoće mogućnosti da taj poremećaj preraste $u$ udes (uslovna verovatnoća da dođe do udesa ako se desio dotični poremećaj, pri čemu se udes može desiti kroz razne realizacije dotičnog polaznog poremećaja). Što je ta verovatnoća veća, to je teži poremećaj, i manja bezbednost proizvoda. Ako su realizacije polaznog poremećaja, koje dovode do udesa, međusobno nezavisne, onda se uslovna verovatnoća prelaska polaznog poremećaja u udes određuje kao suma verovatnoće pojedinačnih realizacija prelaska tog poremećaja $u$ udes. On bi se mogao nazvati ukupnim rejtingom poremećaja, ukazuje na težinu poremećaja sa stanovišta verovatnoće da preraste u udes i odražava nivo bezbednosti proizvoda $u$ datom trenutku.

Jedan od važnih aspekata sistemskog prilaza bezbednosti složenih tehničkih sredstava povezan je sa utvrđivanjem najtežih (najznačajnijih) poremećaja radi preduzimanja efikasnih korektivnih mera. To je osnovni zadatak u upravljanju bezbednošću proizvoda u uslovima ograničenih resursa. Sa tog stanovišta onaj ko upravlja bezbednošću (organ ili lice) treba prvenstveno da predvidi sredstva za otklanjanje uzroka poremećaja koji najviše utiču na bezbednost proizvoda.

Poremećaji eksploatacije sa najvećim rejtingom nazivaju se predznaci udesa, pa se prethodni zadatak svodi na identifikaciju predznaka udesa, radi sprečavanja događanja udesa. Taj prilaz je potpuno u skladu sa idejom stalnog poboljšanja i upravljanja, zasnovanom na činjenicama, kako je to predviđeno standardom ISO 9000:2000.

Operativno upravljanje bezbednošću industrijskih proizvoda, na osnovu identifikacije predznaka udesa, može se ostvariti sledećim nizom aktivnosti [1]: 
1. prikupljanje podataka o poremećajima u ekspolataciji proizvoda za određeni period eksploatacije;

2. proračun rejtinga svakog poremećaja;

3. izdvajanje (identifikacija) predznaka udesa; udesa;

4. analiza bitnih uzroka predznaka

5. uvođenje korektivnih mera za uklanjanje bitnih uzroka predznaka udesa; mera.

6. provera efektivnosti korektivnih

Analiza poremećaja normalne eksploatacije industrijskih proizvoda pokazuje da predznaci udesa imaju, po pravilu, nekoliko osobina:

- nastaju mnogo ređe od običnih poremećaja (u zavisnosti od tipa sredstva na jedan predznak udesa dolazi 10 do 100 običnih poremećaja);

- karakterišu se razgranatim stablom realizacije događaja sa velikim brojem mogućih krajnjih stanja;

- realni i mogući događaji u predznacima udesa obuhvataju i greške čoveka, koji čine do $40 \%$ od ukupnog broja događaja u poremećajima;

- trajanje razvoja predznaka udesa, u proseku, prelazi trajanje razvoja običnog poremećaja.

Mora se istaći da to nisu obavezne osobine svakog predznaka udesa. Zbog toga je za svaku vrstu tehničkog sredstva neophodno prikupljati, sistematizovati i analizirati podatke o karakterističnim nagoveštajima o predznacima udesa, što će omogućiti da se operativnije i bez posebnih metoda analiza identifikuju predznaci udesa.

$\mathrm{S}$ obzirom na to da nema neke poznate granične vrednosti za rejting poremećaja, nije moguće jednostavno defini- sati pravilo za identifikaciju predznaka udesa koje bi se zasnivalo na poređenju dobijene vrednosti rejtinga sa tom graničnom vrednošću. Zbog toga se kao zamena za tu nepoznatu graničnu vrednost može uzeti vrednost $\mathrm{R}_{\mathrm{pr}}$ koja se proračunava na osnovu težine zapaženih poremećaja.

Očigledno da je eksploatacija nekog proizvoda (sredstva), čak i sa visoko pouzdanim elementima, dobrim uputstvima za upotrebu i kvalifikovanim ljudstvom, neizbežno praćena slučajnim poremećajima, od kojih se svaki može okarakterisati određenom vrednošću rejtinga $\mathrm{R}\left(\mathrm{t}_{\mathrm{i}}\right) \mathrm{u}$ trenutku $t_{i}$, koji se kreće $u$ određenim granicama. Te promene vrednosti rejtinga imaju slučajni karakter, ako se pretpostavi da se sistematski uzroci promene rejtinga ne menjanju.

Neka vrednosti rejtinga $R\left(t_{1}\right), R\left(t_{2}\right)$, $\ldots, R\left(t_{r}\right)$, koji odgovaraju trenucima $t_{1}, t_{2}$, $\ldots, t_{r}$, predstavljaju skup vrednosti rejtinga (uzorak) iz neograničenog skupa. Pri normalnoj raspodeli rejtinga $\mathrm{R}$ može se, na osnovu srednje vrednosti rejtinga $R_{s r} i$ disperzije $\mathrm{D}(\mathrm{R})$, koje odgovaraju tom skupu, odrediti granična vrednost rejtinga $R_{p r}$, za koju se sa verovatnoćom poverenja $\gamma>0,5$ može smatrati da će većina vrednosti rejtinga biti u granicama $\left[0, \mathrm{R}_{\mathrm{pr}}\right]$. Vrednosti koje se ne uklapaju u taj interval zadovoljavaju uslov $\mathrm{R}\left(\mathrm{t}_{\mathrm{j}}\right)>\mathrm{R}_{\mathrm{pr}}$, gde je $\mathrm{j}>\mathrm{r}$. Prema tome, sa velikom verovatnoćom $\gamma$ može se smatrati da se poremećaj $u$ trenutku $t_{j}$ može smatrati predznakom udesa, jer se njegova vrednost $R\left(t_{j}\right)$ značajno izdvaja iz ostalih vrednosti rejtinga čije su vrednosti (sa $\mathrm{P}>0,5)$ ispod vrednosti $R_{p r}$.

Vrednost $R_{p r}$ određuje se relacijom [1]:

$$
R_{p r}=R_{s r}+k \sqrt{D(R)}
$$


gde je k koeficijent tolerancije koji se određuje relacijom:

$k \approx U_{p}\left[1+\frac{U_{\gamma}}{\sqrt{2 r}}+\frac{\left(5 U_{\gamma}^{2}+10\right)}{12 r}\right]$

gde je:

$\mathrm{U}_{\mathrm{p}}$ - kvantil normalne raspodele za verovatnoću $P$,

$\mathrm{U}_{\gamma}$ - kvantil normalne raspodele za verovatnoću $\gamma$,

$\mathrm{r}$ - veličina uzorka rejtinga.

Izbor vrednosti P i $\gamma$ zavisi od konkretnog zadatka analize bezbednosti. Kod analize bezbednosti tehničkih sistema te vrednosti se obično uzimaju u granicama 0,95 do 0,99 .
Prikupljeni podaci o nizu poremećaja mogu se, po vremenskom redosledu, naneti na koordinatnu mrežu, što predstavlja kontrolnu kartu bezbednosti, slično kontrolnim kartama kod tehnoloških procesa. Redosled rada sa kontrolnom kartom je sledeći (slika 6):

- za svako sredstvo formira se kontrolna karta koja se popunjava po nastupanju svakog poremećaja i proračunava odgovarajuća vrednost rejtinga;

- kontrolna karta se skladišti u odgovarajućoj banci podataka;

- proračunava se vrednost $R_{p r}$ koja se nanosi na kontrolnu kartu;

- poremećaji kod kojih rejting prelazi vrednost $R_{p r}$ sa velikom verovatnoćom $(\mathrm{P} \gg 0,5)$ smatraju se predznacima udesa;

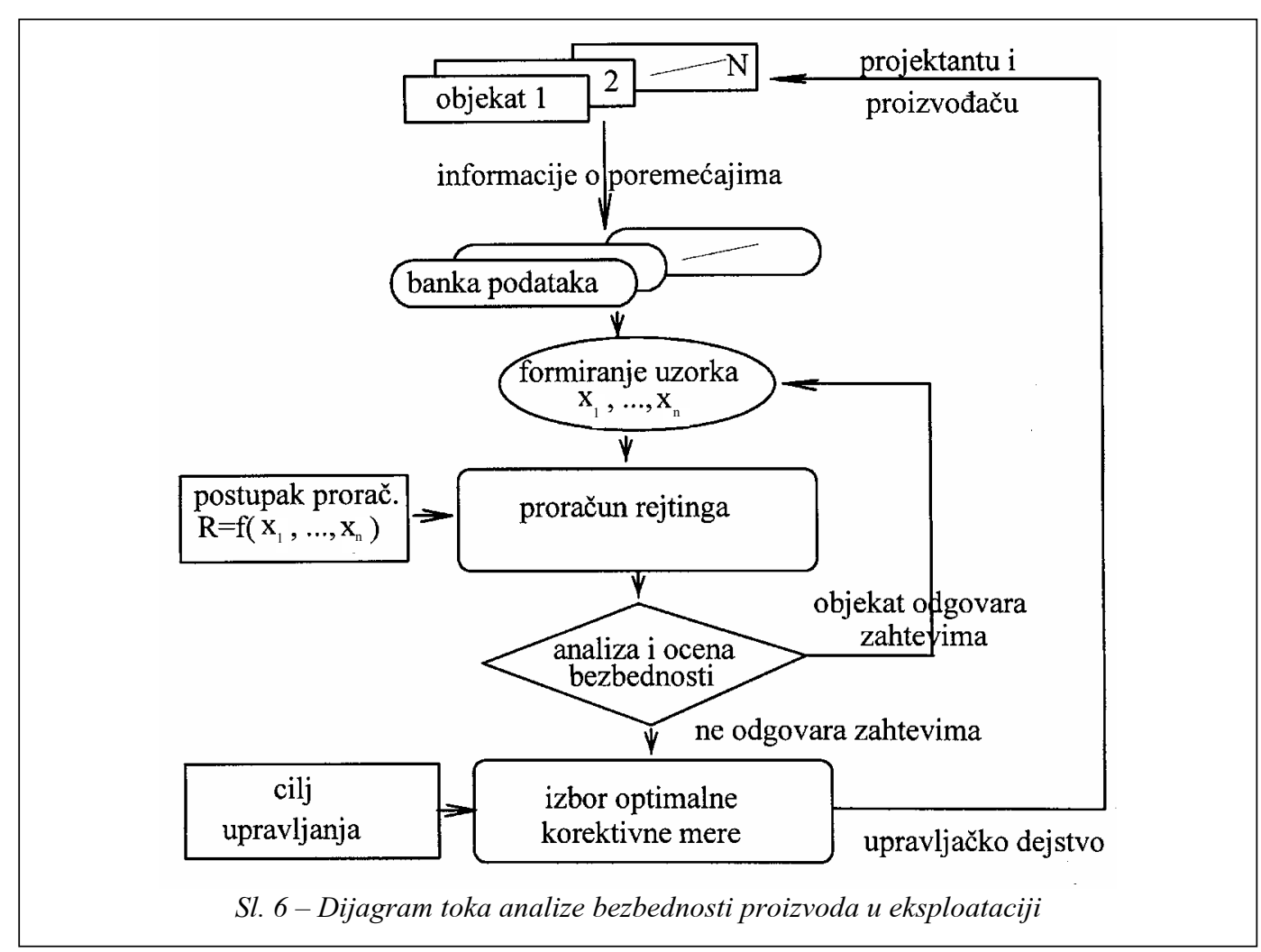


- na zahtev organa ili lica zaduženog za operativno upravljanje bezbednošću, koji donosi odluku, kontrolna karta se daje na uvid (odštampana ili na ekra$\mathrm{nu})$.

Formiranje banke (pregleda) predznaka udesa omogućava naučno zasnovano donošenje odluka o korektivnim merama radi povećanja bezbednosti proizvoda, ocenjivanje efektivnosti tih mera i neprekidno praćenje bezbednosti proizvoda. Osim toga, kontrolne karte omogućavaju procenu da li se proces eksploatacije nalazi u stanju upravljivosti.

U praksi je važan problem izbor perioda posmatranja $\mathrm{T}$ (ili broja poremećaja), neophodnih za proračun $R_{p r}$. To je više inženjerski nego matematički problem. Naime, treba izabrati period eksploatacije $T_{e}$ na kojem poremećaji (sa inženjerske tačke gledišta) imaju slučajni a ne sistematski karakter. Zbog toga je potrebno obaviti inženjersku analizu poremećaja radi utvrđivanja njihovog karaktera.

\section{Zaključak}

U radu su izložene osnove teorije bezbednosti tehničkih sistema. Dat je kratak prikaz razvoja teorije bezbednosti proizvoda, analiziran je odnos pojma pouzdanost i pojma bezbednost proizvoda, kao i drugih pojmova koji se koriste $\mathrm{u}$ istom smislu. Navedene su definicije i odnosi osnovnih pojmova iz oblasti bezbednosti tehničkih sistema, kao i pokazatelja i indikatora bezbednosti tehničkih sistema. Takođe, analizirani su osnovni principi ostvarivanja bezbednosti tehničkih sistema. Detaljnije su razrađeni osnovi statističke analize bezbednosti tehnič- kih sistema $\mathrm{u}$ eksploataciji na osnovu predznaka o mogućnosti nastanka udesa, pri čemu je predstavljena metodologija identifikacije predznaka o mogućnosti nastanka udesa.

Posebna pažnja posvećena je povezanosti teorije bezbednosti tehničkih sistema i teorije pouzdanosti tehničkih sistema, s obzirom na to da je teorija pouzdanosti kod nas poznata i primenjena naučna disciplina, koja se izučava i na osnovnim studijama na nekim fakultetima, a i u Vojnoj akademiji. Procena bezbednosti proizvoda, pored proračuna verovatnoće otkaza, što je jedan od zadataka procene pouzdanosti, zahteva i procenu posledica otkaza, odnosno štete od nastalog otkaza, posebno kada se radi o mogućnosti udesa koji može imati velike društveno-ekonomske i ekološke posledice različitih razmera.

Primena teorije bezbednosti tehničkih sistema u Vojsci, mogla bi imati korisne efekte u preventivi udesa, odnosno vanrednih događaja, pogotovo onih sa teškim posledicama (prvenstveno smanjenju vanrednih događaja sa smrtnim posledicama, povredama i velikim materijalnim štetama).

Sa stanovišta proizvođača, jasno je da je pouzdaniji i bezbedniji proizvod i konkurentniji na tržištu, a da je rizik (politički, ekonomski, tehnički) od ulaganja u nebezbedne proizvode sve veći.

Prikazana metodologija mogla bi se, uz određena prilagođavanja, primeniti ne samo na rad sa tehničkim sistemima, nego i u drugim oblastima, kao što je rad sa ljudima, službe obezbeđenja objekata, posebni oblici nastave, logorovanja, vežbe i slično. 


\section{Literatura:}

[1] Aronov, I. Z.: Inženjerstvo bezopasnosti, Istraživački centa za upravljanje kvalitetom i pouzdanošću, Čačak, 2004.

[2] Pokorni, S.: Pouzdanost i održavanje tehničkih sistema, Vojna akademija, Beograd, 2002.

[3] IEC 60300-1, Menadžment sigurnošću funkcionisanja - Deo 1: Menadžment programom sigurnosti funkcionisanja.

[4] Uputstvo o vanrednim događajima.

[5] JUS ISO/IEC Uputstvo 2: 2001, Standardizacija i srodne aktivnosti - Opšti rečnik, Savezni zavod za standardizaciju, Beograd.

[6] JUS ISO 9000:2001: Sistemi menadžmenta kvalitetom - Osnove i rečnik, Savezni zavod za standardizaciju, Beograd.
[7] Pokorni, S.: Inženjerska primena stabla otkaza u oceni pouzdanosti i raspoloživosti sistema, Istraživački centar za upravljanje kvalitetom i pouzdanošću, Cačak, 2004., str. 77-89, u Papić LJ. (redaktor): Metode analize otkaza sistema - knjiga 2, Analiza stabla otkaza, teorijski i praktični aspekti.

[8] Zeljković, V.: Pouzdanost u praksi, LOLA Institut, Beograd, 2000.

[9] Haimes, Y.: Risk Modelling, Assesment and Management, John Willey and Sons, New York, 1998.

[10] Todorović, J.: Razvoj nauke o održavanju tehničkih sistema, Vojnotehnički glasnik, 2/2003. 

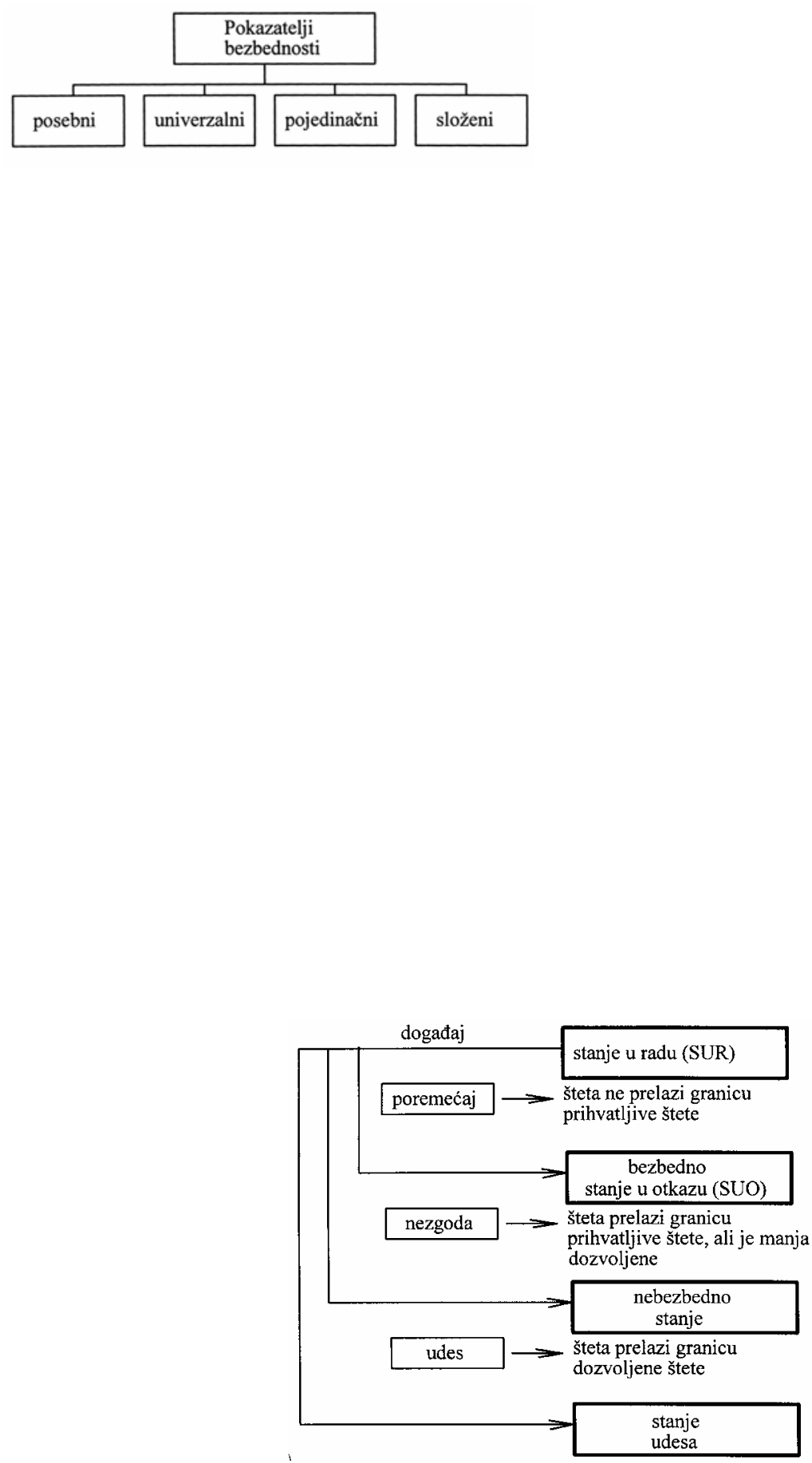

Sl. 1 - Klasifikacija osnovnih događaja i stanja pri analizi bezbednosti proizvoda 


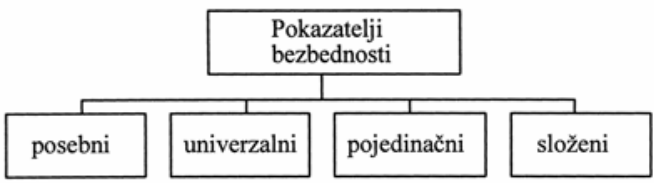

Sl. 2 - Vrste karakteristika bezbednosti

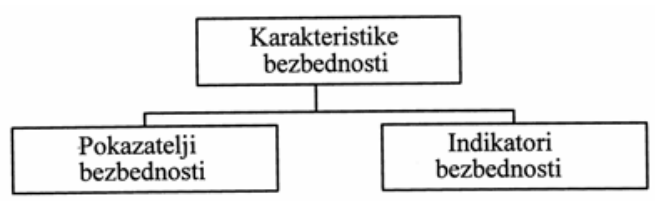

Sl. 3 - Klasifikacija pokazatelja bezbednosti

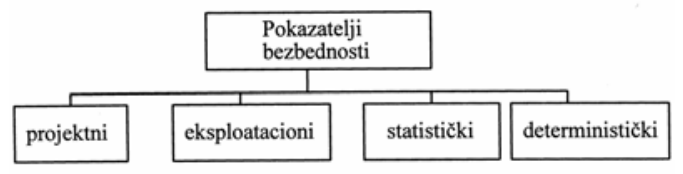

Sl. 4 - Klasifikacija pokazatelja bezbednosti u zavisnosti od faze životnog ciklusa i načina proračuna

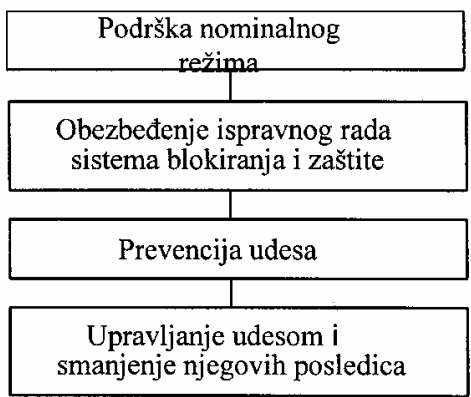

Sl. 5 - Primena principa duboko ešelonirane zaštite 


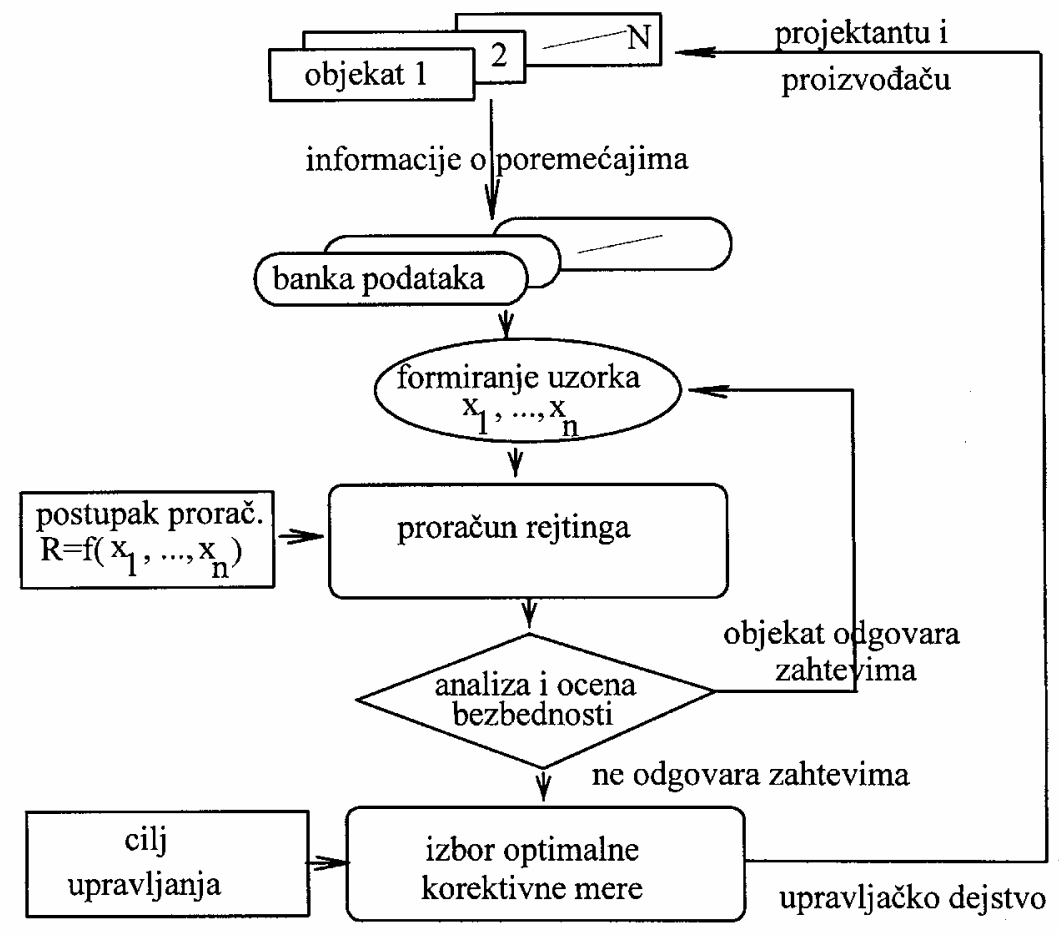

Sl. 6 - Dijagram toka analize bezbednosti proizvoda u eksploataciji 